\title{
GENERAL EQUATIONS FOR A LINEAR CALCULATION OF THIN OR MODERATELY THICK SHALLOW SHELLS
}

\author{
J. M. Martínez Jiménez ${ }^{1}$ J. M. Martínez Valle ${ }^{1}$, A. Martínez Valle ${ }^{1}$, P. Martínez-Jiménez ${ }^{2}$
}

${ }^{1}$ Department of Mechanics of Continuous Medium, Polytechnic School at the University of Córdoba, Spain (jmvalle@uco.es)

${ }^{2}$ Department of Applied Physics, Polytechnic School at the University of Córdoba, Spain

\begin{abstract}
In this paper, we expound a general theory valid for shallow shells, either thin or moderately thick, inspired as a generalization for plates according to the Bolle-Reissner theory, with necessary modifications to include the thinnest shells. The immediate antecedent is constituted by the elastic study of plates shown in the work "General Equations Transformed and Expanded for a General Study of Isotropic Plates Starting with the BolleReissner Theory as a starting point" (submitted also to this Congress). In short, although we esteem this to be an original proposal, it is inspired in a methodology partly known in plates which provides us with a system of differential equations easily tackled by finite differences. Also, as it is valid for moderately thick shells, it does not pose any problems of numerical instability when carrying out studies of thin shells and although it has been constrained to shallow shells, it can be applied to the resolution of a great variety of practical cases given the limitations which have to be imposed in order to consider them as shallow shells (which is usually common in constructive cases).
\end{abstract}

Keywords: shallow shells, linear calculation.

\section{INTRODUCTION}

On the occasion of presenting a theoretical hypothesis, it seemed to us to be imperative to give a brief chronological background if we wished to demonstrate why we felt it necessary to put forward our proposal and show how it may be a step forward in the present state of this science.

With respect to shell structures, the first proposals were based on that corresponding to plates and the first of these theories originated from the hypotheses of Kirchhoff (1876).

This theory was established, although incorrectly, by Aron (1874) but it was Love (1888) who gave it its most adequate form which is still used in some manuals. The problem in its argument was that it conserved some terms of a high order and had eliminated other similar ones, giving it an inconsistency which successive authors resolved either by adding the missing terms or eliminating them.

The basic problem, the expression of the relations between the forces and moments with displacements on the middle surface, had not yet been resolved in a simple way and in this line the following investigations were made, much later on: Galerkin, 1934; Lure 1937, 
1940, 1950. The latter was the first researcher to derive a compact theory but he did not have a sufficient criterion to carry out any simplifications.

These simplifications were established by Novozhilov, 1941 who also managed to ascertain the errors committed by the simplifications of Kirchhoff, 1943.

The contributions of Goldenveizer $(1939,1940)$ permitted the introduction of the compatibility conditions of the deformations and demonstrated the possibility of fulfilling the conditions of equilibrium by means of four deformation functions analogously to what LURE had done.

In the line of simplifying the expressions obtained, Mushtari, 1938, 1947; Feinberg, 1939; Vlasov, 1944, 1949 can be cited.

Parallelly to this school, which was based on the assumptions of Kirchhoff, another was developed following the approach of Cauchy and Poisson for plates which consisted of evolving the functions of stresses and displacements in series of $\mathrm{z}$ (the distance from any point in the plate on the middle plane). The first publication is that of Basset, 1890 which was developed by Kraus, 1929 and Kilchevskii, 1939.

All the previous investigations belong, fundamentally, to Soviet mathematicians. With respect to U.S. research with a totally different thesis, Reissner, 1952 [9] achieved the simplest formulation for shells by establishing two equations as functions of $\mathrm{w}$ (normal displacements of the shell) and F (stress function).

Recent generalizations have improved all these theories. Koiter, 1960; BudianskySanders, 1963; Naghdi, 1963; Goldenveizer, 1967 and Koiter - Simmonds, 1972.

Regarding non-linear theories, the first studies were produced for concrete, simple shapes (O’Donnell, 1933; Reissner, 1950 and Vlasov, 1958. The first publication dealing with the subject in a general way is owed to Novozhilov, 1953. Later on, Kraus (1967) derived the equations in terms of the main lines of the curvature.

So as not to give an onerous list of names, the following are a few of those which figure in the main advances of non- linear theories (Sanders, 1963; Leonard, 1963; Naghdi, 1963; Koiter, 1966 and Marlove, 1968).

With respect to stability studies, those which stand out are by Koiter, 1967, Budiansky, 1968 and Simmons-Danielson, 1972.

\section{BASIC EXPRESSIONS}

Following the Bolle-Reissner hypothesis for plate study, we accept the definition of the components of a shear from any point in the shell

$$
\begin{aligned}
& \mathrm{u}=\mathrm{u}_{\mathrm{o}}+\mathrm{z} \cdot \theta_{\beta} \\
& \mathrm{v}=\mathrm{v}_{\mathrm{o}}-\mathrm{z} \cdot \theta_{\alpha} \\
& \mathrm{w}=\mathrm{w}_{\mathrm{o}}(\alpha, \beta)
\end{aligned}
$$




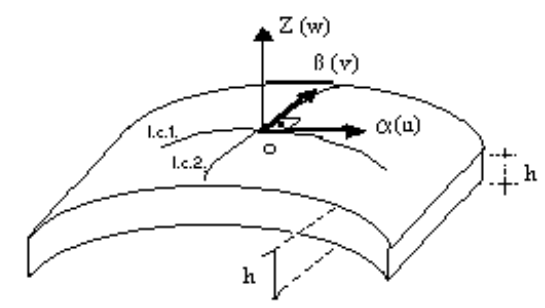

Figure 1. Coordinate System in a shell element

in which $\mathrm{u}_{\mathrm{O}}, \mathrm{v}_{\mathrm{O}}, \mathrm{w}_{\mathrm{O}}$ are the displacements from the point belonging to the middle surface of the shell and $\theta_{\alpha}$ and $\theta_{\beta}$ are the rotations from the normal to the middle surface at that point.

Thus, in accordance with the current state of opinion, a parabolic distribution, all through the thickness, of tangential stresses has been posited [10].

$$
\tau_{\alpha_{z}}=c \cdot G \cdot\left(1-\frac{4 \cdot z^{2}}{h^{2}}\right) \cdot \gamma_{\alpha_{z}} ; \quad \tau_{\beta_{z}}=c \cdot G \cdot\left(1-\frac{4 \cdot z^{2}}{h^{2}}\right) \cdot \gamma_{\beta_{z}} ; \quad \text { whe re } \mathrm{c}=\frac{5}{4}
$$

The linear and angular deformations relative to curvilinear orthogonal coordinates counted along the curvature lines have the expressions $[2,4,10]$

$$
\begin{gathered}
\varepsilon_{\alpha}=\varepsilon_{\alpha_{0}}+\mathrm{z} \cdot \mathrm{k}_{\alpha} \\
\varepsilon_{\beta}=\varepsilon_{\beta_{\mathrm{o}}}+\mathrm{z} \cdot \mathrm{k}_{\beta} \\
\varepsilon_{\mathrm{z}}=0 \\
\gamma_{\alpha \beta}=\gamma_{\alpha \beta_{0}}+2 \cdot \mathrm{z} \cdot \mathrm{k}_{\alpha \beta} \\
\gamma_{\alpha_{z}}=\left(\frac{\mathrm{w}_{\alpha}^{\prime}}{\mathrm{A}}+\theta_{\beta}-\frac{\mathrm{u}_{\mathrm{o}}}{\mathrm{R}_{1}}\right)-\mathrm{z} \cdot \frac{\theta_{\beta}}{\mathrm{R}_{1}} \\
\gamma_{\beta_{z}}=\left(\frac{\mathrm{w}_{\beta}}{\mathrm{B}}-\theta_{\alpha}-\frac{\mathrm{v}_{\mathrm{o}}}{\mathrm{R}_{2}}\right)-\mathrm{z} \cdot \frac{\theta_{\alpha}}{\mathrm{R}_{2}}
\end{gathered}
$$

in which $\mathrm{R}_{1}$ and $\mathrm{R}_{2}$ are the curvature radii and $\varepsilon_{\alpha \mathrm{o}}, \varepsilon_{\beta 0}$ and $\gamma_{\alpha \beta \mathrm{o}}$ are the strains (membrane and shear) on the "middle surface"

$$
\begin{array}{r}
\varepsilon_{\alpha_{0}}=\frac{\mathrm{u}_{\alpha}{ }_{\alpha}}{\mathrm{A}}+\mathrm{v} \frac{\mathrm{A}^{\prime}{ }_{\mathrm{B}}}{\mathrm{A} \cdot \mathrm{B}}+\frac{\mathrm{w}}{\mathrm{R}_{1}}+\frac{\left(\mathrm{w}_{\alpha}^{\prime}\right)^{2}}{2 \mathrm{~A}^{2}} \\
\varepsilon_{\beta_{\mathrm{o}}}=\frac{\mathrm{v}^{\prime}{ }_{\beta}}{\mathrm{B}}+\mathrm{v} \frac{\mathrm{u} \cdot \mathrm{B}_{\alpha}{ }_{\alpha}}{\mathrm{A} \cdot \mathrm{B}}+\frac{\mathrm{w}}{\mathrm{R}_{2}}+\frac{\left(\mathrm{w}_{\beta}\right)^{2}}{2 \mathrm{~B}^{2}}
\end{array}
$$

\footnotetext{
- It can also be assumed that the constant stresses in the thickness reach the same values of the stresses after integrating and imposing the condition of deformation equality energy per section.
} 


$$
\gamma_{\alpha \beta_{0}}=\frac{v^{\prime} \alpha}{A}+\frac{u^{\prime}{ }_{\beta}}{B}-\frac{A^{\prime} \cdot{ }_{\beta} \cdot u}{A \cdot B}-\frac{B^{\prime}{ }_{\alpha} \cdot \mathrm{v}}{A \cdot B}+\left(\frac{u}{R_{1}}-\frac{w^{\prime} \alpha}{A}\right) \cdot\left(\frac{v}{R_{2}}-\frac{w^{\prime} \beta}{B}\right)
$$

Like wise, $\mathrm{k}_{\alpha}, \mathrm{k}_{\beta}, \mathrm{k}_{\alpha \beta}$ are the variations of the bending and torsion curvatures and are expressed as

$$
\begin{gathered}
\mathrm{k}_{\alpha}=\frac{1}{\mathrm{~A}} \cdot \frac{\partial \theta_{\beta}}{\partial \alpha}-\frac{\mathrm{A}_{\beta}^{\prime} \cdot \theta_{\alpha}}{\mathrm{A} \cdot \mathrm{B}} \\
\mathrm{k}_{\beta}=-\frac{1}{\mathrm{~B}} \cdot \frac{\partial \theta_{\alpha}}{\partial \beta}+\frac{\mathrm{B}_{\alpha}^{\prime} \cdot \theta_{\beta}}{\mathrm{A} \cdot \mathrm{B}} \\
2 \mathrm{k}_{\alpha \beta}=\frac{1}{\mathrm{~B}} \cdot \frac{\partial \theta_{\beta}}{\partial \beta}-\frac{\mathrm{A}_{\beta}^{\prime} \cdot \theta_{\beta}}{\mathrm{A} \cdot \mathrm{B}}+\frac{\mathrm{B}_{\alpha}^{\prime} \cdot \theta_{\alpha}}{\mathrm{A} \cdot \mathrm{B}}-\frac{1}{\mathrm{~A}} \cdot \frac{\partial \theta_{\alpha}}{\partial \alpha}
\end{gathered}
$$

In the previous expressions, $\mathrm{A}$ and $\mathrm{B}$ are the coefficients of the first quadratic form of the surface

$$
\mathrm{ds}^{2}=\mathrm{E} \cdot \mathrm{d} \alpha^{2}+\mathrm{F} \cdot \mathrm{d} \alpha \cdot \mathrm{d} \beta+\mathrm{G} \cdot \mathrm{d} \beta^{2},
$$

being $\mathrm{E}=\mathrm{A}^{2}, \mathrm{G}=\mathrm{B}^{2}$ which, in the present case, being $\mathrm{F}=\mathrm{O}$, as the coordinates coincide with the curvature lines, leaves

$$
\mathrm{ds} \mathrm{s}^{2}=\mathrm{E} \cdot \mathrm{d} \alpha^{2}+\mathrm{G} \cdot \mathrm{d} \beta^{2}
$$

From now on, operating in the usual manner, we obtain the strains

$$
\begin{gathered}
\sigma_{\alpha}=\frac{\mathrm{E}}{1-\mu^{2}} \cdot\left(\varepsilon_{\alpha}+\mu \cdot \varepsilon_{\beta}\right) \\
\sigma_{\beta}=\frac{\mathrm{E}}{1-\mu^{2}} \cdot\left(\varepsilon_{\beta}+\mu \cdot \varepsilon_{\alpha}\right) \\
\sigma_{\mathrm{z}}=\mu \cdot\left(\sigma_{\alpha}+\sigma_{\beta}\right) \tau_{\alpha \beta}=\mathrm{G} \cdot \gamma_{\alpha \beta} \\
\tau_{\alpha_{z}}=\frac{5}{4} \mathrm{G} \cdot\left(1-\frac{4 \mathrm{z}^{2}}{\mathrm{~h}^{2}}\right) \cdot \gamma_{\alpha_{z}} \\
\tau_{\beta_{z}}=\frac{5}{4} \mathrm{G} \cdot\left(1-\frac{4 \mathrm{z}^{2}}{\mathrm{~h}^{2}}\right) \cdot \gamma_{\beta_{z}}
\end{gathered}
$$




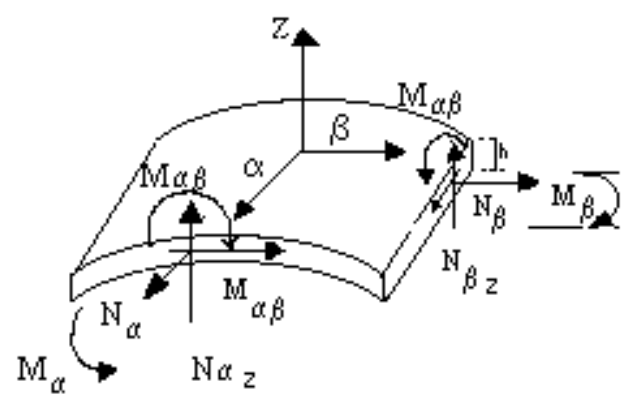

Figure 2.Stresses in shell element

and after integrating in the thickness, we obtained the stresses

$$
\begin{aligned}
& \mathrm{N}_{\alpha}=\iint_{\mathrm{A}} \sigma_{\alpha} \mathrm{dA}=\frac{\mathrm{E} \cdot \mathrm{h}}{1-\mu^{2}}\left(\varepsilon_{\alpha_{0}}+\mu \cdot \varepsilon_{\beta_{0}}\right) \quad ; \quad \mathrm{M}_{\alpha}=\mathrm{D} \cdot\left(\mathrm{k}_{\alpha}+\mu \cdot \mathrm{k}_{\beta}\right) \\
& \mathrm{N}_{\beta}=\frac{\mathrm{E} \cdot \mathrm{h}}{1-\mu^{2}}\left(\varepsilon_{\beta_{\mathrm{o}}}+\mu \cdot \varepsilon_{\alpha_{0}}\right) \quad ; \quad \mathrm{M}_{\beta}=\mathrm{D} \cdot\left(\mathrm{k}_{\beta}+\mu \cdot \mathrm{k}_{\alpha}\right) \\
& \mathrm{N}_{\alpha \beta}=\mathrm{G} \cdot \mathrm{h} \cdot \gamma_{\alpha \beta_{0}} \quad ; \quad \mathrm{M}_{\alpha \beta}=\frac{\mathrm{G} \cdot \mathrm{h}^{3}}{6} \mathrm{k}_{\alpha \beta}
\end{aligned}
$$

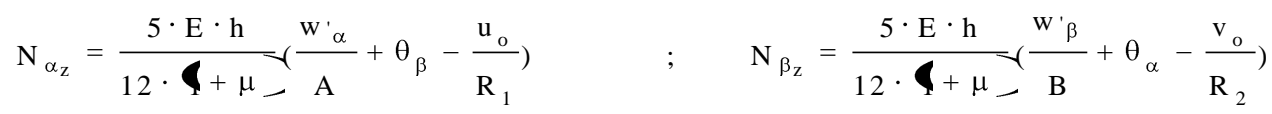

Finally, we had to establish the equilibrium of the "shell element" so that the following equations are arrived at

$$
\begin{gathered}
\frac{\partial}{\partial \alpha}\left(B \cdot N_{\alpha}\right)-\frac{\partial B}{\partial \alpha} \cdot N_{\beta}+\frac{1}{A} \cdot \frac{\partial}{\partial \beta}\left(A^{2} \cdot N_{\alpha \beta}\right)+\frac{A \cdot B}{R_{1}} \cdot N_{\alpha z}+A \cdot B \cdot P_{\alpha}=0 \\
\frac{\partial}{\partial \beta}\left(A \cdot N_{\beta}\right)-\frac{\partial A}{\partial \beta} \cdot N_{\alpha}+\frac{1}{B} \cdot \frac{\partial}{\partial \alpha}\left(B^{2} \cdot N_{\alpha \beta}\right)+\frac{A \cdot B}{R_{2}} \cdot N_{\beta_{Z}}+A \cdot B \cdot P_{\beta}=0 \\
A \cdot B \cdot k_{1} \cdot N_{\alpha}+A \cdot B \cdot k_{2} \cdot N_{\beta}-\frac{\partial}{\partial \alpha}\left(B \cdot N_{\alpha z}\right)-\frac{\partial}{\partial \beta}\left(A \cdot N_{\beta_{Z}}\right)-A \cdot B \cdot P_{z}=0 \\
\frac{\partial}{\partial \beta}\left(A \cdot M_{\beta}\right)-\frac{\partial A}{\partial \beta} \cdot M_{\alpha}+\frac{1}{B} \cdot \frac{\partial}{\partial \alpha}\left(B^{2} \cdot M_{\alpha \beta}\right)-A \cdot B \cdot N_{\beta_{z}}=0 \\
\frac{\partial}{\partial \alpha}\left(B \cdot M_{\alpha}\right)-\frac{\partial B}{\partial \alpha} \cdot M_{\beta}+\frac{1}{A} \cdot \frac{\partial}{\partial \beta}\left(A^{2} \cdot M_{\alpha \beta}\right)-A \cdot B \cdot N_{\alpha_{Z}}=0
\end{gathered}
$$

The equation corresponding to $\Sigma_{\mathrm{M}_{\mathrm{z}}}=0$ which, established in the non-deformed geometry of the element is proved identically, showed us if it is found in the bending geometry which has to be verified:

$$
\frac{\partial \theta_{\alpha}}{\partial \alpha}+\frac{\partial \beta_{\beta}}{\partial \beta}=0
$$




\section{SHALLOW SHELLS AND THE FINITE DIFFERENCE METHOD}

If all the stresses $\mathrm{N}_{\mathrm{i}}$ and $\mathrm{M}_{\mathrm{i}}$ are substituted by their values (23-25) in the differential equation system (26-30), we obtain a system of five differential equations with five unknown values $\left(\mathrm{u}, \mathrm{v}, \mathrm{w}, \theta_{\alpha}, \theta_{\beta}\right)$ which, at least in theory, could be resolved if the contour conditions are taken into account globally.

As it was obvious that the analytic procedures had to be ruled out both because of the complexity of the system and also the necessity of using the methodology for any type of surface being studied, and type of loading, we opted for the finite differences method although it was necessary to overcome the difficulty relative to the fact that the coordinates figuring in the equations are counted according to the lines of curvature.

The traits common to the previous hypotheses, which for us have revealed serious deficiencies, are: the equations are derived in terms of the main lines of curvature and assume the hypothesis of Kirchoff on the deformation and rotation of the normal surface to the shell surface. Except for the few cases of surfaces with simple equations in which the differential equation system can be solved analytically, the first trait makes the possibility of studying more general shapes be rejected as the use of finite difference numerical methods becomes invalidated for the resolution of shells with more complicated equations. The second trait signifies that the study is necessarily constrained to thin shells. With the theoretical thesis presented by us, both deficiencies are rectified although we have been obliged to constrain it to shells with a slight curve. Since the finite differences are expressed in relation to a global Cartesian reference system for all shells, it is necessary for the lines of curvature to coincide with the co-ordinates which only occurred when the coefficients F and F' of the quadratic forms of the surface were zero:

$$
\begin{gathered}
\mathrm{ds}^{2}=\mathrm{E} \cdot \mathrm{d} \alpha^{2}+2 \cdot \mathrm{F} \cdot \mathrm{d} \alpha \cdot \mathrm{d} \beta+\mathrm{G} \cdot \mathrm{d} \beta^{2} \\
\mathrm{~d}^{2} \overrightarrow{\mathrm{p}} \cdot \overrightarrow{\mathrm{n}}=\mathrm{E}^{\prime} \cdot \mathrm{d} \alpha^{2}+2 \cdot \mathrm{F}^{\prime} \cdot \mathrm{d} \alpha \cdot \mathrm{d} \beta+\mathrm{G} \cdot \mathrm{d} \beta^{2}
\end{gathered}
$$

Although it is very well known that this condition is only fulfilled in a reduced number of cases, we have been able to do so, at least to an approximate degree, by limiting the problem to the study of "slightly curved" shells.

Let us say that a shell is a shallow shell [10] when it fulfills the following two conditions, simultaneously, at any point

$$
\mathrm{R}_{\min } \geq 20 \cdot \mathrm{e}, \quad \mathrm{a} \geq 5 \cdot \mathrm{h}
$$

where $R_{\min }$ is the lesser of the radii of curvature, e the thickness of the shell, a the smallest dimension of the shape and $\mathrm{h}$ the difference of the maximum height between points of the shell.

Under these conditions, the Gauss curvature will be small

$$
\left[\frac{1}{\mathrm{R}_{1}} \cdot \frac{1}{\mathrm{R}_{2}} \approx 0\right]
$$

and the Gauss equation 


$$
\frac{\partial}{\partial \alpha}\left(\frac{1}{\mathrm{~A}} \cdot \frac{\partial \mathrm{B}}{\partial \alpha}\right)+\frac{\partial}{\partial \beta}\left(\frac{1}{\mathrm{~B}} \cdot \frac{\partial \mathrm{A}}{\partial \beta}\right)=-\mathrm{k}_{1} \cdot \mathrm{k}_{2} \cdot \mathrm{A} \cdot \mathrm{B} \approx 0
$$

So that if the problem is analyzed in Cartesian coordinates

$$
\mathrm{ds}^{2} \approx \mathrm{dx}^{2}+\mathrm{dy}^{2}, \mathrm{~A} \approx 1, \mathrm{~B} \approx 1
$$

Although additional hypotheses can still be made about the variations of the bending and torsion curvatures and in the equations, we have limited ourselves to the adoption of this first geometrical derivation.

Thus, we are able to affirm that for shallow shells:

- at least approximately for all points:

$$
\left\{\begin{array}{l}
\mathrm{F} \approx 0 \rightarrow \frac{\partial_{\mathrm{Z}}}{\partial_{\mathrm{x}}} \cdot \frac{\partial_{\mathrm{z}}}{\partial \mathrm{y}} \approx 0 \\
\mathrm{~F}^{\prime} \approx 0 \rightarrow \mathrm{z}_{\mathrm{xy}}^{\prime \prime} \approx 0 \\
1+\left(\frac{\partial_{\mathrm{z}}}{\partial \mathrm{x}}\right)^{2} \approx 1 \\
1+\left(\frac{\partial_{\mathrm{z}}}{\partial \mathrm{y}}\right)^{2} \approx 1
\end{array}\right.
$$

- lines coordinates $\approx$ lines of curvature

With these simplifications, the resultant equations (26-30) are

$$
\begin{aligned}
& \frac{\partial \mathbf{N}_{\mathrm{x}}}{\partial \mathrm{x}}+\frac{\partial \mathbf{N}_{\mathrm{xy}}}{\partial \mathrm{y}}+\frac{\mathbf{N}_{\mathrm{xz}}}{\mathrm{R}_{1}}=-\mathrm{P}_{\mathrm{x}} \\
& \frac{\partial \mathbf{N}_{\mathrm{y}}}{\partial \mathrm{y}}+\frac{\partial \mathbf{N}_{\mathrm{xy}}}{\partial \mathrm{x}}+\frac{\mathbf{N}_{\mathrm{yz}}}{\mathbf{R}_{2}}=-\mathbf{P}_{\mathrm{y}} \\
& \mathrm{k}_{1} \cdot \mathrm{N}_{\mathrm{x}}+\mathrm{k}_{2} \cdot \mathrm{N}_{\mathrm{y}}-\frac{\partial \mathrm{N}_{\mathrm{xz}}}{\partial \mathrm{x}}-\frac{\partial \mathrm{N}_{\mathrm{yz}}}{\partial \mathrm{y}}+2 \cdot \mathrm{k}_{12} \cdot \mathrm{N}_{\mathrm{xy}}=\mathrm{P}_{\mathrm{z}} \\
& \frac{\partial \mathbf{M}_{\mathrm{y}}}{\partial \mathrm{y}}+\frac{\partial \mathbf{M}_{\mathrm{xy}}}{\partial \mathrm{x}}-\mathrm{N}_{\mathrm{yz}}=0 \\
& \frac{\partial \mathbf{M}_{\mathbf{x}}}{\partial \mathrm{x}}+\frac{\partial \mathbf{M}_{\mathrm{xy}}}{\partial \mathrm{y}}-\mathbf{N}_{\mathrm{xz}}=0 \\
& \frac{\partial \theta_{x}}{\partial x}=-\frac{\partial \theta_{y}}{\partial y}
\end{aligned}
$$

and the strains: 


$$
\begin{aligned}
& \varepsilon_{\mathrm{xo}}=\mathrm{u}_{\mathrm{x}}^{\prime}+\frac{\mathrm{w}}{\mathrm{R}_{1}}+\frac{\left(\mathrm{w}_{\mathrm{x}}^{\prime}\right)^{2}}{2} \\
& \varepsilon_{\mathrm{yo}}=\mathrm{v}_{\mathrm{x}}^{\prime}+\frac{\mathrm{w}}{\mathrm{R}_{2}}+\frac{\left(\mathrm{w}_{\mathrm{y}}^{\prime}\right)^{2}}{2} \\
& \gamma_{\mathrm{xyo}}=\mathrm{v}_{\mathrm{x}}^{\prime}+\mathrm{u}_{\mathrm{y}}^{\prime}+\left(\frac{\mathrm{u}}{\mathrm{R}_{1}}-\mathrm{w}_{\mathrm{x}}^{\prime}\right) \cdot\left(\frac{\mathrm{v}}{\mathrm{R}_{2}}-\mathrm{w}_{\mathrm{y}}^{\prime}\right)+2 \cdot \mathrm{k}_{12} \cdot \mathrm{w} \\
& \mathrm{k}_{\alpha}=\frac{\partial \theta_{\mathrm{y}}}{\partial \mathrm{x}}, \quad \mathrm{k}_{\mathrm{y}}=-\frac{\partial \theta_{\mathrm{x}}}{\partial \mathrm{y}}, \quad 2 \cdot \mathrm{k}_{\mathrm{xy}}=\frac{\partial \theta_{\mathrm{y}}}{\partial \mathrm{y}}-\frac{\partial \theta_{\mathrm{x}}}{\partial \mathrm{x}}
\end{aligned}
$$

where we have added the terms $2 \cdot \mathrm{k} 12, \mathrm{~N}_{\mathrm{Xy}}$ and $2 \cdot \mathrm{k} 12 \cdot \mathrm{w}$ to include the cases in which the axes $\mathrm{x}, \mathrm{y}$ do not coincide with the projections of the lines of curvature on the plane $\mathrm{x}$ or $\mathrm{y}$.

After substituting the strains in the expressions of the stresses and these, in turn, in the equations of equilibrium (39-44) taking into account the last of these (44) and linearizing, the following system of differential equations is obtained

$$
\begin{aligned}
& \mathrm{u}_{\mathrm{x} 2}^{\prime \prime}+\frac{1+\mu}{2} \mathrm{v}_{\mathrm{xy}}^{\prime \prime}+\frac{1-\mu}{2} \mathrm{u}_{\mathrm{y}^{2}}^{\prime \prime}+\mathrm{w}_{\mathrm{x}}^{\prime} \cdot\left(\mathrm{k}_{1}+\mu \cdot \mathrm{k}_{2}+\frac{5 \cdot(1-\mu)}{12} \mathrm{k}_{1}\right)+(1-\mu) \cdot \mathrm{k}_{12} \cdot \mathrm{w}_{\mathrm{y}}^{\prime}- \\
& -\frac{5 \cdot(1-\mu)}{12} \cdot \mathrm{k}_{1}^{2} \cdot \mathrm{u}+\frac{5 \cdot(1-\mu)}{12} \cdot \mathrm{k}_{1} \cdot \theta_{\mathrm{y}}=-\frac{(1-\mu)}{\mathrm{E} \cdot \mathrm{h}} \cdot \mathrm{P}_{\mathrm{x}} \\
& \frac{1-\mu}{2} \mathrm{v}_{\mathrm{x}^{2}}^{\prime \prime}+\frac{1+\mu}{2} \mathrm{u}_{\mathrm{xy}}^{\prime \prime}+\mathrm{v}_{\mathrm{y}^{2}}+\mathrm{w}_{\mathrm{y}}^{\prime} \cdot\left(\mu \cdot \mathrm{k}_{1}+\mathrm{k}_{2}+\frac{5 \cdot(1-\mu)}{12} \cdot \mathrm{k}_{2}\right)+(1-\mu) \cdot \mathrm{k}_{12} \cdot \mathrm{w}_{\mathrm{x}}^{\prime}- \\
& -\frac{5 \cdot(1-\mu)}{12} \cdot \mathrm{k}_{2}^{2} \cdot \mathrm{v}-\frac{5 \cdot(1-\mu)}{12} \cdot \mathrm{k}_{2} \cdot \theta_{\mathrm{x}}=-\frac{(1-\mu)}{\mathrm{E} \cdot \mathrm{h}} \cdot \mathrm{P}_{\mathrm{y}} \\
& -\Delta \mathrm{W}+\frac{12}{5 \cdot(1-\mu)} \boldsymbol{k}_{1}^{2}+k_{2}^{2}+2 \cdot \mu \cdot k_{1} \cdot k_{2} \ggg+\frac{12}{5 \cdot(1-\mu)}\left(k_{1}+\mu \cdot k_{2}+\frac{5 \cdot(1-\mu)}{12} \cdot k_{1}\right) u_{x}^{\prime}+ \\
& +\frac{12}{5} \cdot k_{12} \cdot u_{y}^{\prime}+\frac{12 \cdot \mathrm{v}_{\mathrm{y}}^{\prime}}{5 \cdot(1-\mu)} \cdot\left(\mu \cdot k_{1}+k_{2}+\frac{5 \cdot \mathbf{\mathbf { C }}-\mu \mathrm{J}_{2}}{12} \cdot k_{2}\right)+\frac{12}{5} \cdot k_{12} \cdot v_{x}^{\prime}+\frac{\partial \theta_{x}}{\partial y}-\frac{\partial \theta_{y}}{\partial x}= \\
& =\frac{12 \cdot(1+\mu)}{5 \cdot E \cdot h} P_{z} \\
& \frac{5 \cdot(1-\mu)}{h^{2}} \cdot w_{y}^{\prime}-\frac{5 \cdot(1-\mu)}{h^{2}} \cdot k_{2} \cdot v+\Delta \theta_{x}-\frac{5 \cdot(1-\mu)}{h^{2}} \cdot \theta_{x}=0 \\
& \frac{5 \cdot(1-\mu)}{h^{2}} \cdot w_{x}^{\prime}-\frac{5 \cdot(1-\mu)}{h^{2}} \cdot k_{1} \cdot u+\Delta \theta_{y}-\frac{5 \cdot(1-\mu)}{h^{2}} \cdot \theta_{y}=0
\end{aligned}
$$

After observing the foregoing system, it is easy to understand that as only the first and second derivatives intervened, its programming by the finite difference method possesses a great facility and, in principle, the procedure was seen to be a promising one. Soon, however, the same phenomena of numerical instability as were found in the study of plates[8] appeared, with the further difficulty that whereas, in plates, at least satisfactory results in the case of thick plates were found, in this typology which by definition is thin, this was not the case. Thus, it has been 
necessary to transform these equations, following the same methodology shown in our aforementioned work [8], with the aim of avoiding the cited inestability phenomena.

\section{TRANSFORMED EQUATIONS}

If the Laplace operator is applied to [51] it is obtained:

$$
\begin{aligned}
\Delta \Delta_{\mathrm{W}} & -\frac{12}{5 \cdot(1-\mu)} \cdot\left(\mathrm{k}_{1}^{2}+\mathrm{k}_{2}^{2}+2 \cdot \mu \cdot \mathrm{k}_{1} \cdot \mathrm{k}_{2}\right) \cdot \Delta \mathrm{w}-\frac{12}{5 \cdot(1-\mu)}\left(\mathrm{k}_{1}+\mu \cdot \mathrm{k}_{2}+\frac{5 \cdot(1-\mu)}{12} \cdot \mathrm{k}_{1}\right) \cdot \Delta_{\mathrm{u}_{\mathrm{x}}}{ }^{\prime}- \\
& -\frac{12}{5} \cdot \mathrm{k}_{12} \cdot \Delta_{\mathrm{u}_{\mathrm{y}}}^{\prime}-\frac{12}{5} \cdot \mathrm{k}_{12} \cdot \Delta_{\mathrm{v}_{\mathrm{x}}}^{\prime}-\frac{12}{5 \cdot(1-\mu)} \cdot\left(\mu \cdot \mathrm{k}_{1}+\mathrm{k}_{2}+\frac{5 \cdot(1-\mu)}{12} \cdot \mathrm{k}_{2}\right) \cdot \Delta_{\mathrm{v}_{\mathrm{y}}}^{\prime}-\frac{\partial}{\partial \mathrm{y}} \Delta \theta_{\mathrm{x}} \\
& +\frac{\partial}{\partial \mathrm{x}} \Delta \theta_{\mathrm{y}}=-\frac{12 \cdot \mathbf{4}+\mu-}{5 \cdot \mathrm{E} \cdot \mathrm{h}} \cdot \Delta \mathrm{P}_{\mathrm{z}}
\end{aligned}
$$

although from between the [52] and [53] it can be established

$$
\begin{aligned}
& -\frac{\partial}{\partial y} \Delta \theta_{x}+\frac{\partial}{\partial x} \Delta \theta_{y}=-\frac{5 \cdot(1-\mu)}{h^{2}} \cdot\left(\frac{\partial \theta_{x}}{\partial y}-\frac{\partial \theta_{y}}{\partial x}-\Delta w\right)-\frac{5 \cdot(1-\mu)}{h^{2}} \cdot\left(k_{2} \cdot v^{\prime}{ }_{y}+k_{1} \cdot u^{\prime}{ }_{x}\right)=-\frac{P_{z}}{D}-
\end{aligned}
$$

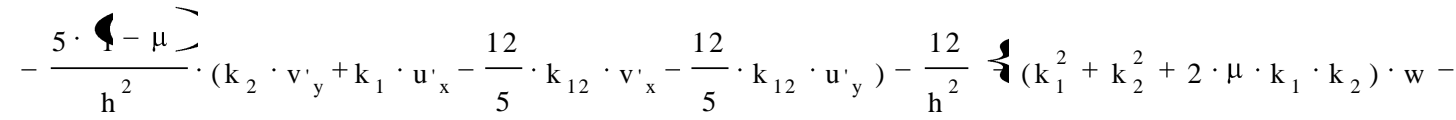

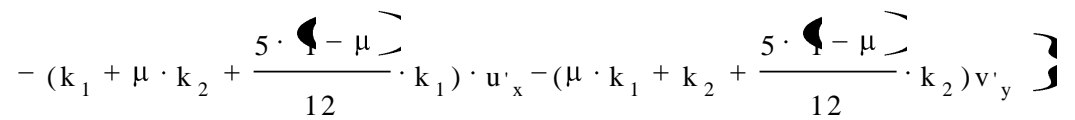

which, once substituted in the previous equation, gives

$$
\begin{aligned}
& \mathrm{u}_{\mathrm{x}^{2}}^{\prime \prime}+\frac{1+\mu}{2} \mathrm{v}_{\mathrm{xy}}^{\prime \prime}+\frac{1-\mu}{2} \mathrm{u}_{\mathrm{y}^{2}}^{\prime \prime}+\mathrm{w}_{\mathrm{x}}^{\prime} \cdot\left(\mathrm{k}_{1}+\mu \cdot \mathrm{k}_{2}+\frac{5 \cdot(1-\mu)}{12} \mathrm{k}_{1}\right)+(1-\mu) \cdot \mathrm{k}_{12} \cdot \mathrm{w}_{\mathrm{y}}^{\prime}- \\
& -\frac{5 \cdot(1-\mu)}{12} \cdot \mathrm{k}_{1}^{2} \cdot \mathrm{u}+\frac{5 \cdot(1-\mu)}{12} \cdot \mathrm{k}_{1} \cdot \theta_{\mathrm{y}}=-\frac{(1-\mu)}{\mathrm{E} \cdot \mathrm{h}} \cdot \mathrm{P}_{\mathrm{x}} \\
& \frac{1-\mu}{2} \mathrm{v}_{\mathrm{x}^{2}}^{\prime \prime}+\frac{1+\mu}{2} \mathrm{u}_{\mathrm{xy}}^{\prime \prime}+\mathrm{v}_{\mathrm{y}^{2}}^{\prime \prime}+\mathrm{w}_{\mathrm{y}}^{\prime} \cdot\left(\mu \cdot \mathrm{k}_{1}+\mathrm{k}_{2}+\frac{5 \cdot(1-\mu)}{12} \cdot \mathrm{k}_{2}\right)+(1-\mu) \cdot \mathrm{k}_{12} \cdot \mathrm{w}_{\mathrm{x}}^{\prime}- \\
& -\frac{5 \cdot(1-\mu)}{12} \cdot \mathrm{k}_{2}^{2} \cdot \mathrm{v}-\frac{5 \cdot(1-\mu)}{12} \cdot \mathrm{k}_{2} \cdot \theta_{\mathrm{x}}=-\frac{(1-\mu)}{\mathrm{E} \cdot \mathrm{h}} \cdot \mathrm{P}_{\mathrm{y}} \\
& \Delta \Delta_{w}-\frac{12}{5 \cdot \boldsymbol{\complement} \mu} \mathbf{\{}\left(k_{1}^{2}+k_{2}^{2}+2 \cdot \mu \cdot k_{1} \cdot k_{2}\right) \cdot \Delta_{w}+\left(k_{1}+\mu \cdot k_{2}+\frac{5 \cdot(1-\mu)}{12} \cdot k_{1}\right) \cdot \Delta u_{x}^{\prime}+ \\
& +\left(\mu \cdot k_{1}+k_{2}+\frac{5 \cdot(1-\mu)}{12} \cdot k_{2}\right) \cdot \Delta_{\mathrm{v}_{\mathrm{y}}^{\prime}} \quad \mathbf{3} \frac{12}{5} \cdot k_{12} \cdot\left(\Delta_{u_{y}^{\prime}}^{\prime}+\Delta_{v_{x}^{\prime}}^{\prime}\right)-\frac{5 \cdot \mathbf{C}-\mu]}{h^{2}} \\
& \cdot\left(k_{2} \cdot v_{y}^{\prime}+k_{1} \cdot u_{x}^{\prime}-\frac{12}{5} \cdot k_{12} \cdot v_{x}^{\prime}-\frac{12}{5} \cdot k_{12} \cdot u_{y}^{\prime}\right)+\frac{12}{\mathrm{~h}^{2}} \cdot\left(\mathbf{R}_{1}^{2}+k_{2}^{2}+2 \cdot \mu \cdot k_{1} \cdot k_{2}\right) \cdot w+
\end{aligned}
$$

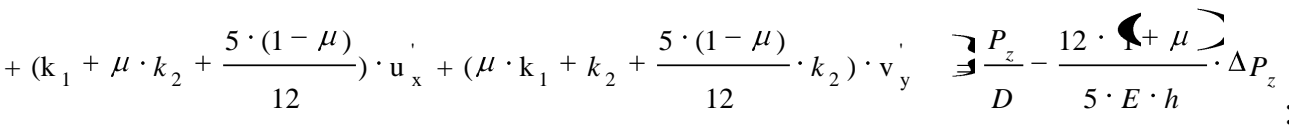

$$
\begin{aligned}
& \frac{5 \cdot(1-\mu)}{h^{2}} \cdot w_{y}^{\prime}-\frac{5 \cdot(1-\mu)}{h^{2}} \cdot k_{2} \cdot v+\Delta \theta_{x}-\frac{5 \cdot(1-\mu)}{h^{2}} \cdot \theta_{x}=0 \text {; }
\end{aligned}
$$




$$
\frac{5 \cdot(1-\mu)}{h^{2}} \cdot w_{x}^{\prime}-\frac{5 \cdot(1-\mu)}{h^{2}} \cdot k_{1} \cdot u+\Delta \theta_{y}-\frac{5 \cdot(1-\mu)}{h^{2}} \cdot \theta_{y}=0
$$

\section{CONCLUSIONS AND EXAMPLES}

From an analysis of the aforementioned system, its facility for programming by finite differences on a rectangular shape can be deduced, as well as if in this analysis $\mathrm{k}_{1}=\mathrm{k}_{2}=\mathrm{k}_{12}=0$ the general linear equations for the calculation of thin, or moderately thick, plates [8] can be found. With regard to the accuracy of the results obtained, some comparative graphs are herewith included among those provided by the type element (Steef) 45 of the well known Ansys program with a subdivision of $16 \times 16 \times 4$, which tackles the calculation by considering the structure as a tridimensional solid body, and those obtained with the previous equations by means of finite differences and a 17x17 mesh (we have obviously verified that a more refined weaving of the mesh did not increase the accuracy significantly), for the following structural shapes: cylindrical shell, elliptic paraboloid and paraboloid velaroidal shell. The results were satisfactory in all cases and it only remains for us to point out the most pronounced "prediction" of the collapse of a paraboloid velaroidal shell in the "kidney" area.

Elliptical paraboloid, fixed in the 4 edges plan $20 \times 20 \mathrm{~m}, \mathrm{H}=1{ }^{\prime} 50 \mathrm{~m}$, thickness =0’08 $\mathrm{m}$.

$$
\mu=0{ }^{\prime} 3, \mathrm{E}=2 \cdot 10^{6} \mathrm{~T} / \mathrm{m}^{2}, \mathrm{Q}_{\mathrm{z}}=2 \mathrm{~T} / \mathrm{m}^{2}
$$

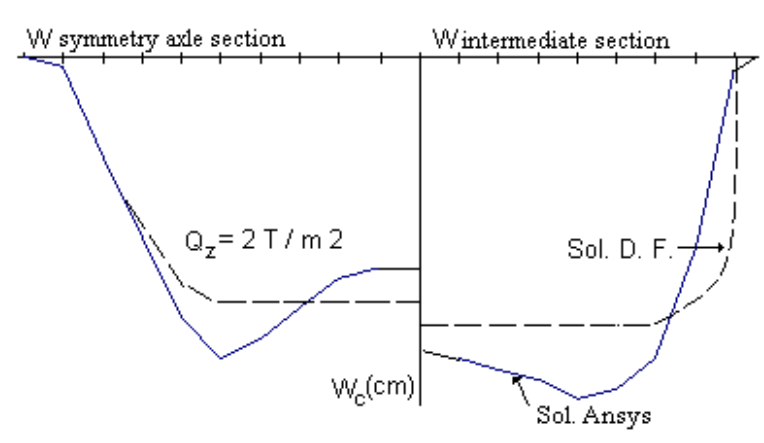

Elliptical paraboloid, fixed in the 4 edges plan $20 \times 20 \mathrm{~m}, \mathrm{H}=1$ '50 m, thickness $=0$ '40 $\mathrm{m}$.

$$
\mu=0{ }^{\prime} 30, \mathrm{E}=2 \cdot 10^{6} \mathrm{~T} / \mathrm{m}^{2}, \mathrm{Q}_{\mathrm{z}}=10 \mathrm{~T} / \mathrm{m}^{2}
$$

Elliptical paraboloid, fixed in the 4 edges plan $20 \times 20 \mathrm{~m}, \mathrm{H}=4 \mathrm{~m}$, thickness $=0$ '08 m.

$$
\mu=0,3, E=2 \cdot 10^{6} \mathrm{~T} / \mathrm{m}^{2}, \mathrm{Q}_{\mathrm{z}}=4 \mathrm{~T} / \mathrm{m}^{2}
$$

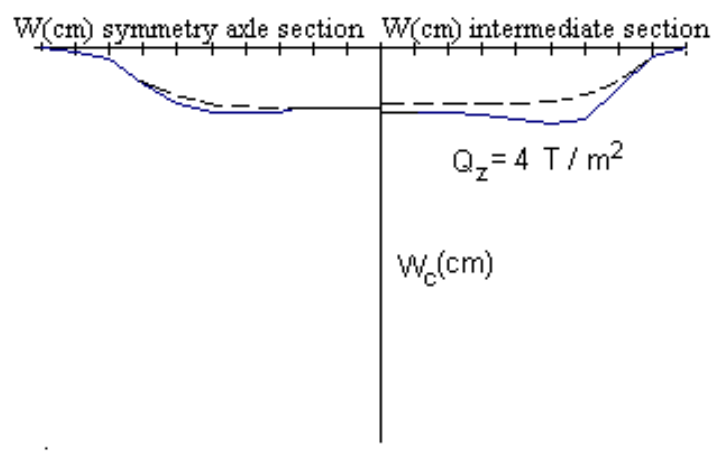

Elliptical paraboloid, fixed in the 4 edges plan 20 x $20 \mathrm{~m}, \mathrm{H}=4 \mathrm{~m}$, thickness $=0{ }^{\prime} 40 \mathrm{~m}$.

$$
\mu=0{ }^{\prime} 3, \mathrm{E}=2 \cdot 10^{6} \mathrm{~T} / \mathrm{m}^{2}, \mathrm{Q}_{\mathrm{z}}=20 \mathrm{~T} / \mathrm{m}^{2}
$$


$W(\mathrm{~cm})$ symmetry axle section $W(\mathrm{~cm})$ intermediate section

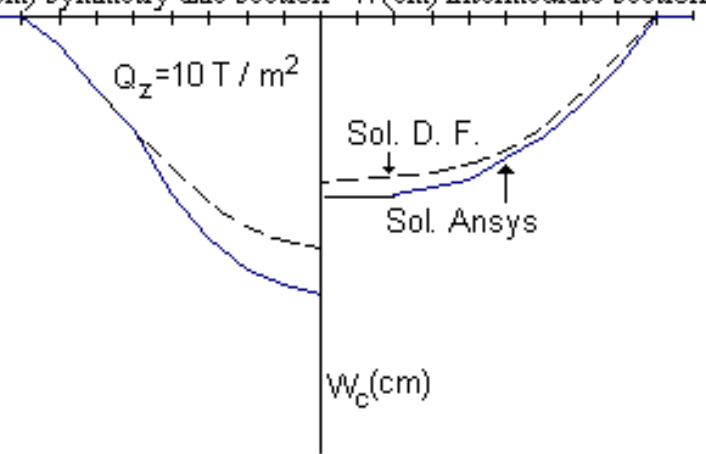

Paraboloid velaroidal fixed in the 4 edges plan $20 \times 20 \mathrm{~m}, \mathrm{H}=4 \mathrm{~m}$, thickness $=0$ ’08 $\mathrm{m}$.

$$
\mu=0{ }^{\prime} 3, \mathrm{E}=2 \cdot 10^{6} \mathrm{~T} / \mathrm{m}^{2}, \mathrm{Q}_{\mathrm{z}}=4 \mathrm{~T} / \mathrm{m}^{2}
$$

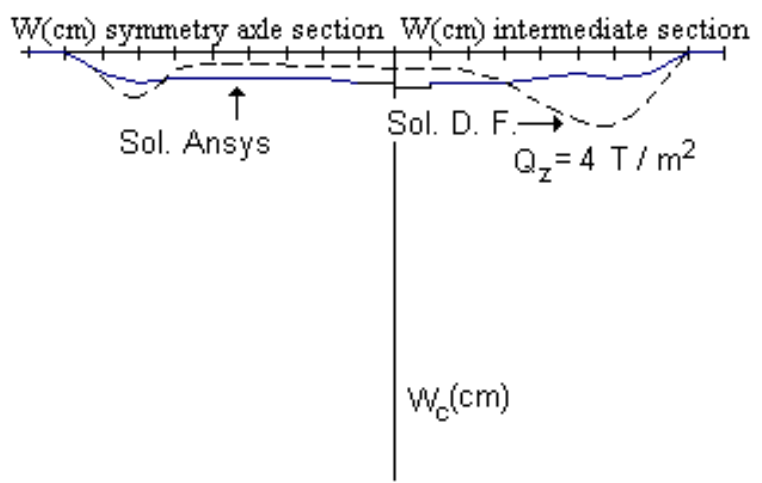

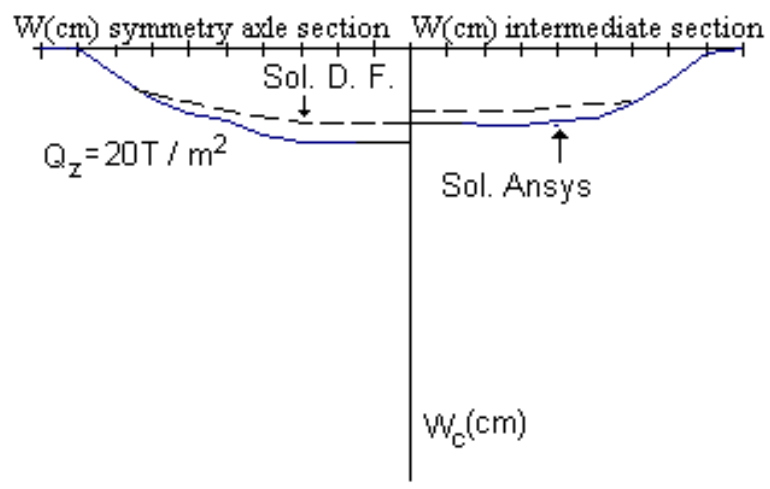

Paraboloid velaroidal fixed in the 4 edges plan $20 \times 20 \times 1{ }^{\prime} 50 \mathrm{~m}$, thickness $=0$ 0'08 m.

$$
\mu=0{ }^{\prime} 3, \mathrm{E}=2 \cdot 10^{6} \mathrm{~T} / \mathrm{m}^{2}, \mathrm{Q}_{\mathrm{z}}=2 \mathrm{~T} / \mathrm{m}^{2}
$$
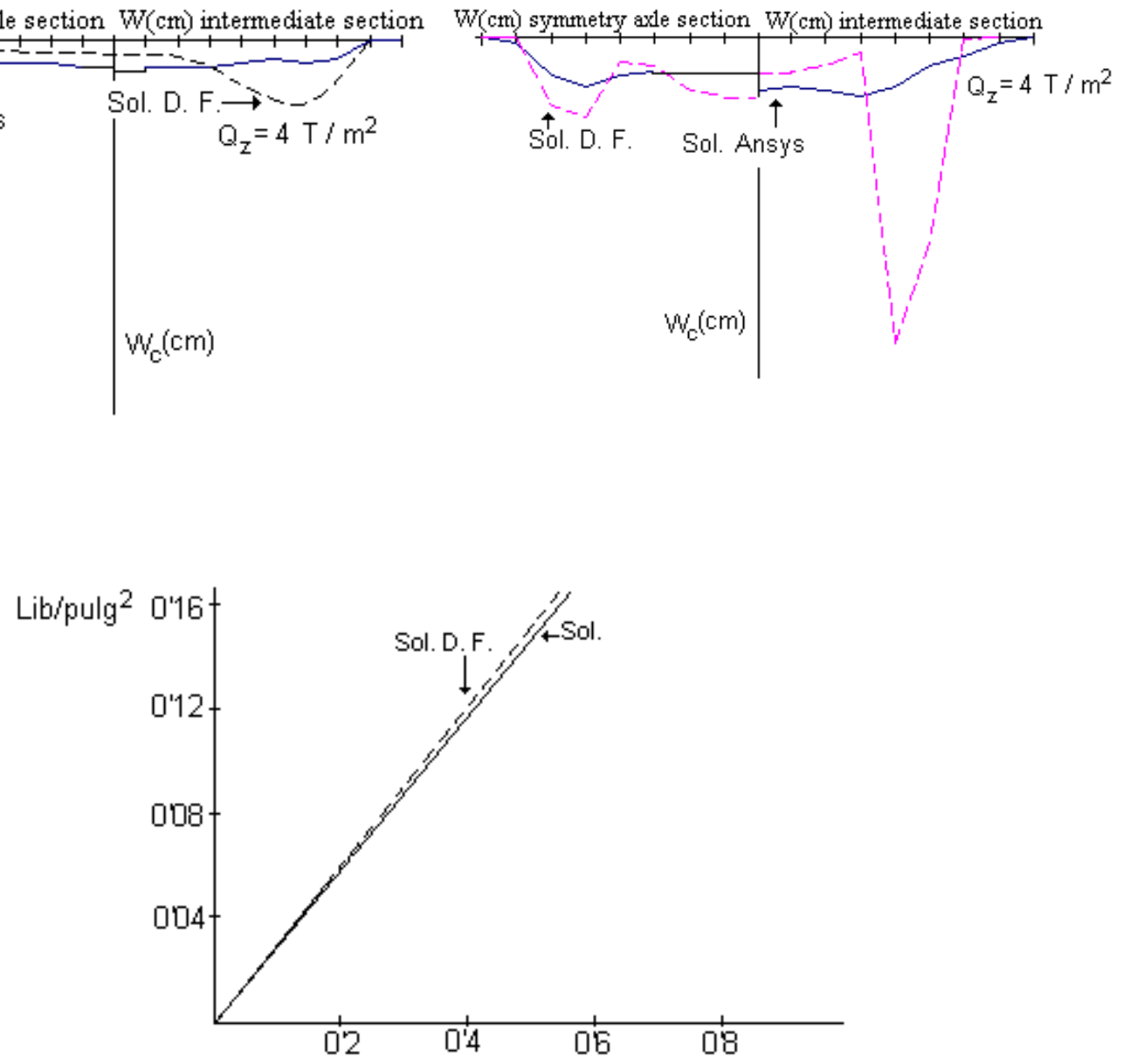

Figure 3. Cilindrical shell

plan $20 \times 20$ ', $\mathrm{H}=0$ '50', thickness $=0$ ' 125

$\mu=0{ }^{\prime} 30, \mathrm{E}=450.000 \mathrm{Lb} / \mathrm{pulg}^{2}$ 


\section{REFERENCES}

[1] Andrés A., Ortega N.F., “An extension of Gaudi`s funicular technique to the conception and generation of structural surfaces". Bulletin I.A.A.S.n' 3,1994.

[2] Bazant Z. P., Stability of Structures. Oxford,1991.

[3] Bolle L. ,Contributión au problème linéaire de flexión d'une plaque e'lastique. B. T. de la Siusse Romande, 1947.

[4] Escrig F. Pandeo de paraboloides hiperbólicos.T.D.,1980.

[5] Köksal "The finite differences analysis of elliptic hyperbolic and revolution paraboloid shells". Bulletin I.A.A.S.n $3,1994$.

[6] Martinez J.M., López R.The non-linear calculation of rectangular projection and shallow shells using the finite differences method. Bulletin I.A.A.S. $\mathrm{n}^{\circ}$ 3,1994.

[7] Martinez J.M.,Pandeo de estructuras laminares velarias sobre un rectangulo (Formulación del elemento curvo isoparamétrico de 30 G.D.L.) T.D.,1989.

[8] Martinez J. M. et al.Equations transformed and expanded for a general study of isotropic plates with the Bolle - Reissner theory as a starting point, $10^{\text {th }}$ World Congress on Computational Mechanics, 2012.

[9] Reissner E. On the theory of bending of elastic plates, 1945.

[10] RekachV.G. Problemas de la Teoría de la Elasticidad, Editorial MIR ,1978.

[11] Voyiaddjis G. Z. and Karamanlidis D. Advances in the Theory of Pates and Shells, Elsevier Science Publishers B.V., Amsterdam, The Netherlands, 1990. 